\title{
From event analysis to global lessons: disaster forensics for building resilience
}

\author{
Adriana Keating ${ }^{1}$, Kanmani Venkateswaran ${ }^{2}$, Michael Szoenyi ${ }^{3}$, Karen MacClune ${ }^{2}$, and Reinhard Mechler ${ }^{1}$ \\ ${ }^{1}$ International Institute for Applied Systems Analysis, 2361 Laxenburg, Austria \\ ${ }^{2}$ ISET International, Boulder, 80303, USA \\ ${ }^{3}$ Zurich Insurance Group, 8002 Zurich, Switzerland
}

Correspondence to: Adriana Keating (keatinga@iiasa.ac.at)

Received: 12 February 2016 - Published in Nat. Hazards Earth Syst. Sci. Discuss.: 29 February 2016

Accepted: 25 May 2016 - Published: 8 July 2016

\begin{abstract}
With unprecedented growth in disaster risk, there is an urgent need for enhanced learning and understanding of disasters, particularly in relation to the trends in drivers of increasing risk. Building on the disaster forensics field, we introduce the post-event review capability (PERC) methodology for systematically and holistically analysing disaster events, and identifying actionable recommendations. PERC responds to a need for learning about the successes and failures in disaster risk management and resilience, and uncovers the underlying drivers of increasing risk. We draw generalisable insights identified from seven applications of the methodology to date, where we find that across the globe policy makers and practitioners in disaster risk management face strikingly similar challenges despite variations in context, indicating encouraging potential for mutual learning. These lessons highlight the importance of integrated risk reduction strategies. We invite others to utilise the freely available PERC approach and contribute to building a repository of learning on disaster risk management and resilience.
\end{abstract}

\section{Introduction}

Disaster risk is growing at an unprecedented rate; in some low- and middle-income countries, growth in disaster risk is outpacing economic growth (UNISDR, 2015). Globally the number of disaster events and the magnitude of their impacts are increasing (CRED, 2015; Munich Re, 2014; Swiss Re, 2015). The headline message from the Global Assessment Report on Disaster Risk Reduction 2015 is that, while the Hyogo Framework for Action 2005-2015 (United Nations,
2005) has overseen a successful decline in disaster mortality (in relative terms), in most places there has not been significant success in arresting the substantial increase in monetary losses from disasters (UNISDR, 2013, 2015). These disaster impacts have profound knock-on effects on development and well-being, are typically borne by the most vulnerable and undo many development successes achieved before these impacts occur.

There is much more that could be done to reduce disaster risk and prepare for future disasters. The 2015-2030 Sendai Framework for Disaster Risk Reduction (United Nations, 2015) promotes the urgent need for learning about and understanding disasters in the societal processes in which they arise. Featured prominently is the need to understand - and eventually arrest - trends in the factors which are leading to the increase in risk; namely hazard, exposure, and vulnerability (IPCC, 2012). Similarly, Gunderson (2010) identifies learning as central to building disaster resilience under significant uncertainty. Strengthening disaster risk management (DRM) requires looking back and learning from past disaster events in order to achieve a forwardlooking, resilience-building mentality. In the context of everexpanding insight regarding the science of natural hazards and risks as well as increasing technical capacity to manage events and risk, the research community recognises the need for an approach that builds on structured and quick post-event learning in order to provide actionable input for informing the policy and practice of disaster risk reduction (DRR). 
Work on forensics, while often not called this, has focused on root cause analysis (Wisner et al., 2004), meta-analytical reviews of similar events or thematic issues (such as the roles of deforestation, insurance, or megacities; White et al., 2001; Mitchell, 1999), longitudinal analysis to observe the impacts of multiple disasters in a specific location (Erikson, 1976; Oliver-Smith and Hoffman, 1999), and the development of retrospective scenarios (Jones et al., 2008). The Forensic Investigations of Disasters (FORIN) project (Burton, 2010; IRDR, 2011) is a key initiative with multiple applications, which examines the context, root causes, and consequences of disasters as well as damage causality, in order to identify best- or worst-practice criteria for DRR. A key aspect of this kind of work is the use and communication of science-based information.

Our paper builds on this line of research and introduces the post-event review capability methodology (PERC; Venkateswaran et al., 2015) for analysing disaster events in any context. PERC responds to a need for learning about the successes and failures in DRM and resilience, and uncovers the underlying drivers of why risk is increasing. We draw key lessons learnt from seven applications of the methodology to date from both developed and developing country contexts and in both urban and rural areas. It is evident from these seven PERC studies that, across the globe, policy makers and practitioners in DRM face strikingly similar challenges despite variations in context, indicating encouraging potential for mutual learning. The PERC methodology and associated repository of analyses are a contribution to the provision of accessible, consistent and generalisable insights and practical recommendations about disaster risk; disaster risk management; and disaster resilience in both theory and practice.

PERC studies explore the trends in the drivers of increasing risk (hazard, exposure, and vulnerability) in detail by systematically asking questions to uncover the root causes, successes, and failures in DRR measures. Increasing exposure absolute number, value and/or portion of assets, and people located in high-risk areas - is the biggest driver of increasing risk. What are the drivers in this exposure growth and what are the opportunities to address them? Trends in physical and social vulnerability vary considerably across the world depending on the development context; what is important for each country or region? Finally, there is a need to learn and understand how all phases of DRM are being undertaken; what are the success stories and areas for improvement? The PERC approach takes a systematic and holistic perspective, considering the environmental and physical/infrastructural factors, together with human, social, political, and institutional ones.

While the PERC approach is structured around the DRM cycle, it also explores disaster resilience more broadly (of which DRM is just one part). Disaster resilience is "the ability of a system, society, or community to pursue its economic and social development and growth objectives while managing its disaster risk over time in a mutually reinforcing way"
(Keating et al., 2014, p. 7). Critical within this conceptualisation is that disaster resilience includes both the ability to learn from the disturbance and to incorporate risk into broader decisions - this is fully compatible with the needs set out in the Sendai Framework for Disaster Risk Reduction (United Nations, 2015). Within this discourse, resilience is not simply recovering from a shock to the pre-shock state; in particular, bouncing back to a previous, "stable" state is problematic if that state was vulnerable to begin with. Disaster resilience also ensures human well-being by bouncing forward and building back better, so that future shocks have a lesser impact. Further to this, we note that the environments within which risk and well-being are realised are continuously changing, a situation which is expected to continue with rapid socio-economic, demographic, and climatic changes. Hence building disaster resilience is a constant, adaptive process. Disaster resilience is about living and thriving - in the face of disaster risk and uncertainty.

The challenge of learning from disasters, and subsequently taking better decisions to reduce risk and enhance disaster resilience, is not something that is easily achieved. This is well established in the literature (Meyer, 2010; Birkland, 2009; Donahue and Tuohy, 2006). Meyer (2010) finds three key cognitive barriers to learning about disaster mitigation: "(1) an instinct to learn by trial and error that subconsciously rewards us for not mitigating more often than for mitigating; (2) a tendency to base decisions on poor mental models of the physical mechanics of hazards; and (3) a tendency to be lured to take risks by a misplaced confidence in our ability to survive hazards, no matter how severe" (Meyer, 2010, 187-188). At the social or institutional level Meyer argues that a fourth factor compounds these: "a tendency to entrust decisions about how much (and when) to invest in mitigation to agents who are not likely to suffer the direct consequences of poor decisions" (Meyer, 2010, p. 188). Indeed we are witnessing significant bias against taking collective ex-ante action to address growing disaster risk, seen in the fact that the vast majority of resources go towards emergency relief and response rather than toward ex-ante action to address growing disaster risk (Benson and Twigg, 2004; Hoff et al., 2003; Kellett and Caravani, 2013). Despite decades of research on disasters, the perception that disasters are random "acts of God" remains (Lavell and Maskrey, 2014; Cardona, 2003). There is also an asymmetry in both those who can act vs. those who are most impacted, and in the locations where action is needed vs. where impacts occur, which can disincentivise action (Bull-Kamanga, et al., 2003). Thus, although there is ample evidence that investing in risk mitigation is extremely cost effective (Mechler, 2016), nonetheless it remains politically unattractive. The benefits of risk reduction and resilience building need to be demonstrated and promoted much more broadly to incentivise those to take action who seem not to be profiting initially from those actions.

While much learning on the evolution and realisation of risk is happening already, widely available insights tend to 
be at the global level (such as the Global Assessment Reports) or at the specific institution or case study level. These are often very conceptual and academic, and/or highly contextually specific and performance-focused (Donahue and Tuohy, 2006; Birkland, 2009). The field of disaster forensics emerged to fill the gap in learning between the global and specific levels. Disaster forensics borrows the term "forensics" from the field of criminal investigation, because it denotes a consistent approach to developing a full analysis of an event and its root causes. While enabling a systematic approach, disaster forensics is open to new insights (for example, the build-up of risk in an area) and encourages a diligent and flexible analysis. In this way a PERC review, which is a type of forensic analysis, is able to identify and contextualise the most important aspects of risks and the resulting events, while at the same time providing a consistent approach which facilitates cross-situational learning.

The purpose of the PERC approach is to contribute to breaking down the above biases against ex-ante action. PERC is designed to undertake a holistic analysis of the disaster event at whatever level it occurred - a critical but not often undertaken approach, as disasters often cross intra- and international jurisdictional boundaries. PERC accomplishes this by providing a structured and replicable approach to learning about all the phases of the DRM cycle, all aspects of resilience, and contextualising this within the broader trends and the whole spectrum of the disaster event. It then provides this information exactly when it is most salient after a disaster; at the level of an individual PERC study, the analysis is typically conducted in the weeks or months following an event. The focus is on what did and did not work across the whole DRM cycle, where there was resilience, and where it could be built across the linked social-environmental system. There is a strong focus on institutional factors, not only in the response and recovery phase, but also on how these contributed to the evolution of both risk and resilience in the area prior to the disaster event.

The audience of PERC is not one particular stakeholder or field. A PERC analysis is designed to be accessible and understood by all stakeholders, thereby informing discussions on disaster risk and potential resilience-building interventions. PERCs are designed to aid stakeholders in understanding the complex institutional contexts within which they are operating. The analysis is focused on identifying critical gaps and actionable opportunities for mitigating disaster risk relevant to multiple stakeholders within the local social, institutional, and economic context. The recommendations outlined within each report are designed to be realistic and implementable within existing institutional structures. It should be noted that PERC does not design specific interventions or provide a framework for recovery. One of the fundamental features of a PERC is that it is, ideally, independent from vested and/or commercial interests, a characteristic which enables analysts to truly uncover and outline learning. The final PERC report is publicised widely, targeted at key actors and decision makers, and is freely available.

By replicating the PERC approach in multiple locations, there is a developing, freely available repository of PERC studies which is already yielding generalisable insights. Below, we outline the PERC approach and how it differs from other types of analyses. We then present our first analysis of consolidated insights generated to date, which are organised around trends in hazard and vulnerability; crisis preparedness and response; recovery and reconstruction; prospective risk reduction ${ }^{1}$ and exposure growth; and corrective risk reduction. At the end of the paper we outline how the metaanalysis presented here provides insights into the improvement of the PERC methodology itself, and our vision for enhanced learning of disaster risk management and disaster resilience globally. The development of the methodology guide and initial applications have been led by Zurich Insurance Group within the remit of its corporate responsibility program and Zurich's global flood resilience alliance, in collaboration with ISET-International and with support from the International Institute for Applied Systems Analysis. This paper invites any interested party to utilise our freely available methodology and contribute to the developing repository for global benefit.

\section{The PERC meta-structure and methodology}

The PERC studies conducted to date have taken 3-6 months from the initial planning to the publication of the final report. This timeline is dependent on size and scope of the study and the local context. The PERC methodology guide (Venkateswaran et al., 2015; henceforth "the guide") describes what is analysed in a PERC report. Broadly, it focuses on the resilience of people, systems, and legal and cultural norms before, during, and after a disaster. The narrative of what happened and the analysis of why is structured around the disaster risk reduction and management cycle. The stages of this cycle are defined as follows:

1. Risk reduction and preparedness phases include the build-up of risk and actions to avoid further build-up (prospective risk reduction), as well as action taken to reduce already existing risk (corrective risk reduction). Here the analysis focuses on the long-term processes, land-use and infrastructural change, and crisis preparedness, which includes "preparedness for response", including community or localised awareness and action.

\footnotetext{
${ }^{1}$ UNISDR (2009) defines prospective risk reduction as "Management activities that address and seek to avoid the development of new or increased disaster risks. Comment: This concept focuses on addressing risks that may develop in future if risk reduction policies are not put in place, rather than on the risks that are already present and which can be managed and reduced now."
} 
2. Response phase explores actions taken during and immediately after an event to manage, contain, and/or reduce impacts. This phase covers institutional coordination of a disaster response, as well as evacuation, immediate loss reduction and containment, search and rescue, emergency relief, and so on.

3. Recovery phase looks at actions taken after the disaster event, in either the short or medium-term depending on when the analysis is being undertaken, and relevance to the event in question and institutional context. It explores what was/is being done to aide people to cope with and recover from the impacts of disasters, restoration of services and business, and reconstruction of physical damage.

The three major components of resilience explored within the PERC approach (Friend and MacClune, 2012) are as follows:

- Systems are the "what" component of resilience, which refers to the combination of ecosystems and infrastructure systems, and the services they provide.

- Institutions are the "how" component of resilience, which refers to the rules, norms, beliefs, or conventions that mediate human relations and interactions, control access to resources, goods and services, assets, information, and influence.

- Agents are the "who" component of resilience, which refers to the people and their organisation of all types (households, communities, private and public sector organisation, companies), their capacity to interact with their socio-environmental system, and their relative sets of assets, entitlements, and power. An agent's ability to access and influence systems - their resilience - is differentiated on the basis of assets, entitlements, and power.

None of these three components (agents, systems, and institutions) are isolated silos; they all exist in constant dynamic interaction with one another. Therefore, institutions influence systems and agents, systems influence institutions and agents, and agents influence systems and institutions. These dynamics provide a key opening for learning and change (Friend and MacClune, 2012).

PERC reports follow a standardised structure (as set out in the guide), which helps to ensure the event is analysed holistically without overlooking elements or connections, for example, due to data availability or analyst bias. This structure places an emphasis on mapping out the institutional system in which the event took place as a means to identify key actors, understand decision making and communication processes, and identify points of failure and gridlock which can deeply impede DRM processes and resilience. This structure also aids in cross-PERC comparisons and drawing out generalisable lessons. Following an executive summary, the report presents an introduction which includes the motivation for the report, a short overview on the disaster itself as well as the risk landscape, study methodology, and a map of the study location. Section I sets out the physical context of the disaster event, including how this event compares to other events which have occurred in the location. Section II explores the socio-economic disaster landscape by looking at whether and how risk has built-up in the location in the previous two decades, as well as the physical and social vulnerability profile. Section III is a factual description of what happened in the preparation, response, and recovery phases, which particularly identifies successes, failures, and who has and has not benefited. Section IV presents key insights, looking at identified successes across the whole DRM cycle, and the drivers of these successes. It then looks at critical gaps in the DRM cycle and what is constraining action in these areas.

Section V of a PERC report presents recommendations and opportunities for action. It should be noted that recommendations do not only focus on what went wrong, but also strengthen what worked well. Recommendations are designed to be actionable, feasible, equitable, and just. They should be realistic given the social, political, geographical, and economic context. Particular attention is paid to the needs and perspective of the most marginalised and vulnerable groups. Again following the state of the art (e.g. UNISDR, 2015), recommendations pay particular attention to emphasising prospective risk reduction pathways and avoiding the rebuilding of risk into the system. The recommendations focus on identifying the where and how (Tyler and Moench, 2012).

1. Infrastructure and ecosystems can be strengthened to reduce their fragility and to reduce the risk of cascading failures.

2. Capacities of agents can be built to anticipate and develop adaptive responses, and to access and maintain core systems; this incorporates the importance of human, social, and natural capital for both DRM and wellbeing.

3. Effective responses to system vulnerability and the ability of agents to take action to prevent and manage disasters are constrained by institutional factors.

4. Blockages for learning are present and how they can be overcome to ensure learning processes from past events are effective and used to improve resilience before the next event.

The first step of conducting a PERC study is to carry out a literature review and desk research of newspaper articles, peerreview articles, reports etc. to understand and document as much as possible about the event and the discourse surrounding it. Technical information on the hazard, its return period, and severity are also collected if available. This provides the 
Table 1. PERC reports reviewed for the analysis.

\begin{tabular}{|c|c|c|c|}
\hline PERC report name & Country & $\begin{array}{l}\text { Flood event } \\
\text { date }\end{array}$ & Citation \\
\hline $\begin{array}{l}\text { Central European floods 2013: } \\
\text { a retrospective }\end{array}$ & $\begin{array}{l}\text { Germany (focus), Austria, } \\
\text { Czech Republic, } \\
\text { Switzerland }\end{array}$ & June 2013 & $\begin{array}{l}\text { Zurich Insurance Group } \\
(2014 \mathrm{c})\end{array}$ \\
\hline $\begin{array}{l}\text { Floods in Boulder: a Study of } \\
\text { Resilience }\end{array}$ & USA & $\begin{array}{l}\text { September } \\
2013\end{array}$ & MacClune et al. (2014) \\
\hline $\begin{array}{l}\text { After the storm: how the UK's flood } \\
\text { defences performed during the surge } \\
\text { following Xaver }\end{array}$ & UK & $\begin{array}{l}\text { December } \\
2013\end{array}$ & $\begin{array}{l}\text { Zurich Insurance Group } \\
\text { (2014b) }\end{array}$ \\
\hline $\begin{array}{l}\text { Balkan floods of May 2014: challenges } \\
\text { facing flood resilience in a former war } \\
\text { zone }\end{array}$ & $\begin{array}{l}\text { Bosnia and Herzegovina, } \\
\text { Serbia, Croatia }\end{array}$ & May 2014 & $\begin{array}{l}\text { Zurich Insurance Group } \\
\text { (2015) }\end{array}$ \\
\hline $\begin{array}{l}\text { Emmental, Switzerland floods of July } \\
\text { 2014: on a hot, sunny day, a flood alert! }\end{array}$ & Switzerland & July 2014 & $\begin{array}{l}\text { Zurich Insurance Group } \\
(2014 a)\end{array}$ \\
\hline $\begin{array}{l}\text { Urgent case for recovery: what we can } \\
\text { learn from the August } 2014 \text { Karnali } \\
\text { River floods in Nepal }\end{array}$ & Nepal & August 2014 & MacClune et al. (2015) \\
\hline $\begin{array}{l}\text { Morocco floods of 2014: what we can } \\
\text { learn from Guelmim and Sidi Ifni }\end{array}$ & Morocco & $\begin{array}{l}\text { November } \\
2014\end{array}$ & $\begin{array}{l}\text { Zurich Insurance Group } \\
\text { and Targa-AIDE (2015) }\end{array}$ \\
\hline
\end{tabular}

analyst(s) with the necessary context and helps direct fieldwork. Fieldwork necessitates visiting the affected areas and speaking with individuals and organisations affected and/or involved with the event. The PERC guide suggests how to identify interviewees and conduct interviews, which forms the bulk of PERC fieldwork. People and organisations targeted for interviews are identified via desk research and partner-organisation contacts; from there a "snowball sampling" method is used for generating more interviewees until the analyst is comfortable in writing all sections of the report. Informal interviews, for example with households or businesses impacted by the disaster, are also encouraged in order to broaden the perspective and validate insights.

The PERC approach presented here is distinct from currently available approaches to forensic disaster analysis and impact assessment; it fills a gap and complements them, rather than replacing them (see Szoenyi et al. (2016) for further details of the difference between PERC and other forensic disaster analysis methods). It differs from Post Disaster Needs Assessments (PDNAs) (GFDRR, 2013) because it is focused on longer-term, system-wide learning rather than establishing immediate post-disaster needs. Nor is it focused on stocktaking immediate or long-term financial or physical impacts. In contrast to Damage, Loss and Needs Assessments (DALA, see GFDRR, 2010) and the CEDIM's Forensic Disaster Analysis project (CEDIM, 2015), PERC is not focused on providing direct support for prioritising immediate response and recovery needs. Unlike the CEDIM (2015) project and for earthquakes, EEFIT's (EEFIT, 2016) systematic forensic methodology, PERC is not focused on providing technical- or engineering-oriented information on the hazard and/or the performance of the built environment. Lastly, PERC shares many similarities with, yet remains uniquely distinct from, the Forensic Investigations of Disasters (FORIN) project (IRDR, 2011). Our comparison of the FORIN methodology and conducted studies shows that FORIN is strong in in-depth, contextually specific insights into risk: a critical piece of the disaster learning puzzle. PERC, on the other hand, is somewhat more applied and conducted over a tighter time frame (possibly with fewer resources), with a view to producing actionable recommendations in the medium term following a disaster, and with the consolidation of these key findings for building long-term resilience in mind.

\section{What we have learnt so far from disaster forensic PERC reports}

Our meta-analysis of seven PERC analyses conducted between 2013 and 2015 identifies a number of common lessons despite extremely varied contexts. Table 1 lists the PERC reviewed reports; it should be noted that while they are all flood events, the methodology is designed to be applicable to multiple hazard types.

A PERC was conducted on the central European floods of June 2013 in Germany, Austria, Czech Republic, and 
Switzerland because of the severity of the event (Zurich Insurance Group, 2014c). After an already very wet May, which had led to ground saturation in vast areas, heavy rainfall led to surface run-off which produced riverine flooding in tributaries and major rivers - in particular the Danube and Elbe. Wide areas of Germany, Austria, and the Czech Republic were inundated, 25 people were killed, and tens of thousands forced to evacuate. Estimates of total economic losses range from between EUR 11.9 billion and EUR 16 billion. This PERC pays particular attention to exploring how lessons learnt during similar floods in 2002 had been incorporated into policy and action in the 2013 event. It also includes a prospective look at scenarios for a similar (hypothetical) event occurring again in 2023. Considering the status of Germany as one of the wealthiest and intensively governed countries on Earth, the insights and need for action outlined in the PERC report is sobering, and show just how universal the challenges of managing disaster risk are.

The flooding, which resulted from hurricane Xaver in the UK, was the worst event since 1953 (Zurich Insurance Group, 2014b). Hurricane Xaver, and the further storms which followed, came with damaging wind speeds and tidal forces. The storm which hit the east coast of the UK was estimated to be a 1-in-100-year event. In the UK alone, more than 10000 people were evacuated and approximately 1400 properties flooded. The PERC report finds that the lack of fatalities, and the fact that financial losses were less than they could have been, can be attributed to physical defenses implemented post-1953.

The PERC analysis of floods in the Balkans (Bosnia and Herzegovina, Serbia, and Croatia) in May 2014 reports that the severe flooding was in places the worst it had been in 120 years (Zurich Insurance Group, 2015). Torrential rain triggered flash floods and major flooding in rivers within the Danube watershed. Approximately 80 people were killed, and 3 million others were impacted. Economic loss in the region is estimated to be EUR 3.3 billion. Floods also triggered fatal landslides in oversaturated hilly areas. Devastatingly, the flood dislodged land mines which had previously been mapped, rendering information about mine location inaccurate.

Severe flooding in the Emmental valley in Switzerland in July 2014 provided an interesting opportunity to test the PERC methodology for a smaller yet locally severe event (Zurich Insurance Group, 2014a). An intense local thunderstorm caused the Emme river to burst its banks in the upper watershed, while downstream, where the river empties, the weather was hot and sunny; a situation which put warning and preparation systems to the test. The flood which eventuated is estimated to be a 1-in-300-year event; the PERC analysis finds that a good monitoring and warning system, and lessons learnt from previous floods in 2005 and 2007, meant that no lives were lost. Success of preparation, however, should not overshadow a more systemic issue of asset location in the high-risk areas. This PERC is a strong exam- ple of using the methodology to identify both what is working well and what needs improvement, which is useful not only for the specific location but serves as a good practice example for others.

The first PERC conducted by an organisation other than Zurich Insurance Group addressed severe flooding in Boulder County, Colorado in September 2013 (MacClune et al., 2014). The floods, which resulted from a 1-in-1000year rainfall event, caused catastrophic damage county-wide. Within the county, four lives were lost and damage to properties and infrastructure was widespread, costing hundreds of millions of dollars. Due to high flood waters, extreme hydrological behaviour, and changes in major drainages, the National Guard undertook the largest air evacuation since hurricane Katrina and rescued more than 1100 stranded residents. Yet, most systems were maintained, and the response and recovery were strong, well coordinated, and effective. This PERC very explicitly uses the systems, institutions, and agents framework to analyse the event and how elements of preparedness, response, and recovery in each category contributed to resilient outcomes.

The first PERC to be conducted in a developing nation was undertaken in Nepal, following widespread flooding in the Karnali basin in western Nepal in August 2014 (MacClune et al., 2015). Together with Zurich Insurance, this PERC was conducted in partnership with ISET International, ISETNepal and Practical Action Nepal. As an immediate result of the flooding, an estimated 222 people were killed, and approximately 120000 others suffered major impacts. Infrastructure and property were subjected to extensive damage. The floods, believed to be the worst ever recorded, are estimated at a 1-in-1000-year event. This PERC shows the universal applicability and flexibility of the methodology, and findings highlight the similarities between flood resilience challenges across the globe.

The most recent available PERC report, at the time of writing, was undertaken in response to floods in Morocco in November 2014, and focuses on the towns of Guelmim and Sidi Ifni (Zurich Insurance Group and Targa-AIDE, 2015). This PERC was conducted in collaboration with Targa-AIDE, a Moroccan NGO. The floods resulted in over 30 deaths and heavy damage to critical infrastructure. This PERC highlights the power of early warning and mobilisation, since the flood in Sidi Ifni was less devastating because authorities and communities learnt from impacts in Guelmim, which occurred a few days earlier. It emphasises what is working well in Morocco, as well as areas for improvement, which again are strikingly similar to lessons from other PERCs.

We now draw out the lessons from the PERCs described above to identify key commonalities and generalisable insights. It should be noted that the lessons presented here do not include every lesson from every PERC, as many were naturally context-specific; what we draw out here are the lessons which were recurrent. The structure of these con- 
solidated lessons is based on thinking outlined in Keating et al. (2014) on disaster resilience, which describes the systemic nature of disaster resilience and emphasises the critical feedbacks which are leading to exposure growth; the concern at the centre of the Sendai Framework (United Nations, 2015). First we identify common trends in hazards to explore perception around flood severity over time and attribution to climate change. Next we look at trends in physical and social vulnerability, and what role this plays in determining disaster risk. We then turn specifically to the DRM cycle and identify lessons about crisis preparedness and response capacities. Recovery and reconstruction are explored next, particularly linking back to the vulnerability discussion. Recovery and reconstruction lead, in the next cycle, to prospective risk reduction: the interconnected issues of prospective risk reduction (or lack thereof), and exposure growth, are a key lesson from the PERCs which reinforces the message of the Sendai Framework. We then draw out lessons regarding reliance on physical infrastructure for corrective risk reduction and the inducement of the levee effect. Finally we present cross-cutting lessons which are relevant right across the DRM cycle and for disaster resilience more broadly.

\subsection{Hazard and vulnerability}

\subsubsection{Hazard frequency and severity are increasing, and this must be taken into account in order to maintain protection levels}

Frequency and severity of hazards (i.e. extreme precipitation, storm surge, wildfire weather conditions) are factors of risk expected to increase under climate change (IPCC, 2012). Several of the reviewed PERCs have included available science on how the frequency and severity of the hazard in question in the study location might alter under climate change. Future climatic scenarios were reviewed within the central European floods PERC within the section exploring preparedness for a similar event in 2023. Likewise, it was assessed how flood losses of similar intensity as the ones experienced in Switzerland in 2013 and 2015 could return much more frequently in the future. Climate modelling contains uncertainty about future frequency and severity of flood weather, but finds significant cause for concern, particularly in smaller watersheds. Jongman et al. (2014) concluded that annual flood losses in the European Union could amount to EUR 23.5 billion by 2050, up from EUR 4.2 billion annually in the period 2000-2012. Similarly, climate change scenarios indicate a shifting storm surge frequency in the UK, where hurricane Xaver hit. For the Karnali basin floods in Nepal, research collated for the PERC report indicates that climate change is likely to intensify precipitation-driven flooding. When contextualised within the whole PERC report, we find a generalisable lesson: if a certain level of protection (e.g. to a 1-in-100-year flood) is to be maintained, it is not enough to rely on historical data, because the goalposts are shifting.
Hazards themselves are changing, and future planning must take this into account.

\subsubsection{Most vulnerable groups need to be included in planning, response, and recovery}

The Nepal and Morocco PERCs have the most sophisticated discussion of social vulnerability; we speculate that this is due to the fact that they were conducted in collaboration with NGOs and/or because poverty and social inequality are considered to be more salient issues in developing countries. Both reports highlight the fact that it is the most marginalised groups who are living in the most hazardous areas. Indeed, they often live in these areas because they are the risky areas nobody else wants. Furthermore, these groups are found to be most frequently excluded from recovery processes, which has long-term negative impacts on development and wellbeing for them and their whole society.

\subsubsection{Vulnerability of critical infrastructure needs to play a more prominent role in disaster planning}

The PERCs on the central European, Balkan, Karnali, and Morocco floods describe worrisome circumstances where the vulnerability of critical infrastructure in the event of disasters is not taken into account in planning. For example, the Karnali PERC describes how raised dirt roads provide some flood protection, but when these makeshift embankments are overtopped, the transportation system grinds to a halt, magnifying impacts and hindering recovery. Similarly in Morocco, roads were often built along dry stream beds, and were naturally destroyed during floods. The PERCs emphasise the importance of understanding not only the vulnerability of critical infrastructure due to the primary impacts of disasters, but also the potential for impacts to cascade into systemic failures of secondary effects. In Morocco, floods resulted in telephone networks being disabled, which severely hampered emergency response capacity. As described in the Balkan floods PERC, when a power station was inundated by flood waters, hundreds of thousands of households were left without electricity during a critical time. The Morocco floods PERC also reports that the destruction of the city's sewage pumping station caused noxious secondary effects.

\subsection{Crisis preparedness and response}

\subsubsection{Improving forecasting is an essential first step in disaster resilience}

Hazardous event forecasting is a necessary first step in disaster risk management, and information technology is making it more and more accessible. It is striking that improvements in forecasting was a recommendation in PERCs across very different contexts. The central European floods PERC, which focused on one of the wealthiest and most technologically advanced countries on earth, Germany, found that 
meteorological and hydrological forecasting needs improvement to the state of the art, which is reasonable for the region. The Balkan floods PERC reinforces recommendations put forward by local assessments that "now is a good time to upgrade flood forecasting capabilities". Again in Karnali and Morocco, even modest improvements in rainfall observation and run-off measurement data would provide significant benefits and are not out of the reach of these governments. Ultimately, this needs to link into a publicly available data hub of weather data, linking these together to an integrated rainfall-to-run-off model.

\subsubsection{Early warning systems save lives}

Consolidating findings from the PERC studies, we find that early warnings save lives and allow for the protection of assets, but only if they operate within an effective early warning system. An early warning system is not just the presence of a warning about an event, it is also a means to distribute, interpret, and respond to that warning so that action is taken. Flood early warning systems functioned well in the central European, hurricane Xaver, Boulder and Emmental floods. The lack of fatalities in the Emmental floods is credited to learning and subsequent improvement of early warning systems which took place following previous floods. Recent improvements in community-based early warning systems in the Karnali basin in Nepal are also credited with saving livings and provide a powerful example for the rest of the country. In Boulder, existing warning systems and strong public messaging resulted in far fewer losses than emergency management personnel expected for an event of that size. In both the Balkan and Moroccan floods, however, while meteorological and hydrological information was present, the absence of a well-integrated warning systems meant this information was largely ineffective. There is a need to establish early warning systems with clear roles and responsibilities in communication and action-taking.

\subsubsection{Institutional capacity is the key to successful response operations}

A central lesson from the PERCs is that much of the successes or failures of crisis response comes down to the capacities of relevant institutions to plan and coordinate for a disaster event. In the Karnali floods in Nepal, the PERC shows how local community disaster management committees provided the vast majority of response, while national government and NGO response was slow and poorly coordinated. In contrast, in Boulder, pre-existing relationships between a range of institutional players allowed for rapid response and resource mobilisation. The Balkan floods PERC specifically identifies the need for established evacuation procedures to manage evacuation when it is required; here the combination of poor early warning systems, little public awareness, and poor evacuation coordination resulted in the loss of life.
Similarly in the Moroccan floods, the lack of preparation and subsequent time lag in coordination efforts meant that the response to the flood in Guelmim was largely ineffectual; a situation that was thankfully improved in Sidi Ifni.

\subsection{Recovery and reconstruction}

\subsubsection{Improve incentives to build back better}

"Building back better" is a term which has become a staple of the disaster management landscape in recent years. The futility of rebuilding to the same level of risk after a disaster and the benefit of using reconstruction to rebuild to a better standard is intuitively simple. It is not enough to understand that building back better is a good idea, we must understand the practicalities of doing this, which is where the PERC approach can assist. The central European flood PERC describes the need for incentives which encourage building back better (i.e. reduce physical vulnerability) and/or allow for relocation (i.e. reduce exposure). Currently, compensation schemes (both public- and private-insurancebased) struggle with this because of a tradition of compensating only to the previous standard. The report goes on to highlight the fact that this is economically efficient in the long term. Furthermore, the Xaver PERC describes how a desire to rebuild quickly and minimise business interruption severely inhibits building back better, as this requires a more time-intensive planning process. In the Karnali basin, lack of resources and recovery support leave very little capacity for building back, let alone building back better.

\subsubsection{Recovery support must be carefully designed and implemented}

One key area where the PERC reports reviewed show a distinction between developed and developing country contexts, is in their discussion about recovery support. In the case of Germany and the UK, the PERCs highlight significant concern about the potential disincentive for undertaking risk reduction when government fully reimburses recovery costs (a problem also known as "moral hazard"). In Nepal and Morocco however, concerns with recovery support are centred on the fact that those most in need of support, the poorest or most marginalised groups, are those who have the least access to it. In Boulder, although recovery support was technically available to marginalised households, many of these householders are undocumented migrants who were unwilling to come forward for assistance out of fear of being reported. In all situations, we see that the seemingly simple concept of supporting recovery can have long-term impacts on risk and vulnerability. 


\subsection{Prospective risk reduction and exposure growth}

\subsubsection{Exposure is growing rapidly}

Five of the seven reviewed PERC reports act as case studies supporting the concern about exposure growth emphasised by the UNISDR (2013) and reflected in the focus of the Sendai Framework for Disaster Risk Reduction (United Nations, 2015). In the central European, Xaver, Balkan, Karnali, and Morocco flood PERCs, increasing population and asset density in high-risk areas is identified as a key driver of increasing risk and a vital concern for the future. In Germany and the UK, this build-up is occurring despite the existence of robust government institutions. In the Balkans, Morocco, and Nepal, increased urbanisation is often unofficial or illegal. The PERC analysis of the Morocco floods emphasises the changing nature of floods in the region. While traditionally floods were considered to be beneficial for crop irrigation, changing demographic, and socio-economic dynamics, particularly urbanisation, has seen them turn from benefit to disaster. This insight is a prime example of a lesson running through many of the PERCs - that our traditional or historical understanding of flood dynamics is inadequate for future planning. The PERC analyses emphasise that it is not enough to attempt to correct risk after it has built up, but that prospective risk reduction is the only way to truly arrest growth in disaster risk. This is particularly compelling considering the problems with corrective risk reduction - namely the levee effect - described below.

\subsubsection{Urgent need for disaster-informed investment and land-use planning}

The central European PERC states that "[t]he best approach is to build outside of flood hazard zones. If this is not possible, then natural retention offers advantages over artificial measures (for example, levees or mobile projection). Beyond this, reducing vulnerability and stringent planning to deal with emergencies is necessary". We see here how the systemic approach of the PERC highlights the importance of prospective risk reduction - a real cure to the problem rather than just treating the symptom. While Germany does prohibit building in legally designated flood hazard zones, there are generous exceptions granted. In the Karnali basin in Nepal, there is substantial concern that a planned hydropower plant in the upper watershed will increase flooding. It is not unreasonable to expect that even in a resource-constrained environment, a project as large as this would be informed by risk analysis.

\subsection{Corrective risk reduction}

\subsubsection{Disaster regulating environmental planning is extremely effective and should be the first line of defense}

The use of environmental planning techniques to manage flood waters (for example protection or reforestation in the upper watershed, static or controlled retention areas) is found to be highly effective. The central European floods PERC emphasise the benefit of park-like areas, which have the cobenefit of community recreational facilities during nonflood times, as particularly successful at managing flood waters in Germany and Austria. Also in Germany, learning and resultant diligent flood water retention planning since floods in 2005 and 2007 saw significantly reduced impacts in 2014. The central European floods also provides a good practice example on the success of polders (areas set aside for flood water retention), especially controlled polders, which are only opened at strategic times during the peak of floods. In Boulder, resilience was significantly enhanced by "greenways", which provide recreational opportunities and transportation alternatives, but also allow safe overflow space for floodwaters. The Morocco PERC describes the importance of reforestation, and its interaction with physical defenses which are not as effective as they could be without such green infrastructure initiatives.

\subsubsection{Well designed, maintained and monitored physical defenses are effective, but can increase risk in the long-term}

Findings from the central European floods PERC shows that well designed, maintained, and monitored dams and risk reduction measures along rivers do make a significant difference to impacts. Similarly, coastal defenses provided significant protection to the English coast during hurricane Xaver; in this case, the PERC estimates at least a 6:1 return on protection investment. The value of well-designed, maintained and monitored physical protection infrastructure is seen in the Balkan, Karnali, and Morocco floods, unfortunately via counterfactual examples; in these areas many levees and other defenses were poorly designed and maintained, leading them to fail, in some cases even before they were overtopped. A key aspect of levee design highlighted by a number of PERC reports, is the ability to "fail well". Despite some successes in the central European floods, there were also a number of devastating levee breaches and levees working at full capacity. This highlights the importance of incorporating best-practice levee design, which allows the levee to fail gradually and non-catastrophically when it is overwhelmed.

However, the PERC analyses also recurrently identify the devastation of the "levee effect" - where levees (or other types of physical defenses) lull people into a false sense of security and induce asset build-up in the "protected" area. 
While levees, particularly if well designed, maintained and monitored, reduce risk in the short term, they may be inadvertently increasing risk in the long-term. The central European floods PERC documents massive levee breaches in Germany and Austria, which caused severe flooding in towns and the cutting-off of major highways. The presence of, and trust in, levees had resulted in low flood awareness in these towns. In Nepal, poorly designed levees coupled with the fact that they are designed in ways which attract development, mean that long-term risk is increasing rapidly. In Germany levees in other areas held but were nonetheless tested right to their limit; understanding this is an important lesson for the future - just because things worked well this time, it does not mean there is no risk. Even countries like Germany are not immune from this type of unintended outcome in terms of long-term risk, so while the reports show the success of dams, this is not done without strong qualifications. Overall we find that physical defenses should not be solely relied upon; instead they should be well integrated into a holistic DRM strategy. In the case of floods, this should be managed at the watershed level.

\subsubsection{Regulation enforcement is a systemic issue}

The presence and enforcement of building codes and other regulations in at-risk areas is found to be a systemic problem. The central European floods PERC finds that Germany suffers from unenforced regulations designed to reduce flood risk to existing buildings. Similarly in Nepal and Morocco, land use and building regulations are in place but are not accompanied by enforcement, likely due to lack of institutional capacity and household resources. The fact that a country like Germany struggles with regulation enforcement is a testament to the challenge. Boulder takes this a step further and highlights the challenges of regulation when the physical landscape changes.

\subsection{Cross-cutting lessons}

\subsubsection{Need to improve disaster risk awareness and information}

Many of the PERCs call for increased awareness about disaster risk amongst individuals, businesses, and officials alike. The Xaver PERC finds that many people were unaware that warnings (which were present and of high technical quality) applied to them, which points to issues within the targeting and communication aspects of early warning systems. The central European floods PERC emphasises the need for improved and targeted awareness around flood risk amongst individuals and businesses, particularly as some businesses did not have any flood plans in place, despite being located in hazardous areas. In Nepal, many people were totally unaware of their flood risk or what they might do to reduce or survive it when a flood eventuates. In Morocco, neither residents nor tourists were aware of the flood hazard in the region, and ignored warnings, resulting in forced evacuations. Information on hazardous areas is essential to all stages of the DRM cycle. While information about a hazard does not in itself induce action, it is a necessary first step for taking action. In relation to hazard maps specifically, the central European, Nepal, and Morocco flood PERCs all call for better flood hazard maps so that individuals, businesses, and authorities know where flood hazard zones are and so that lack of this basic information does not impede risk reduction.

\subsubsection{Improve language on event return periods}

Several of the PERC analyses report the use of return period language when discussing disasters and how this creates a problematic perception that, for example, "since there was a 1 -in-100-year event 5 years ago, there will not be another one for 95 years". This is particularly seen in the central European floods, where the event of similar magnitude, a 1-in-100-year event, was experienced in 2002, meaning the 2013 event was in this way unexpected. The recurrent recommendation is to instead discuss disaster risk in terms of probability, so instead of "a 1-in-100-year event", one should say that "the event has a $1 \%$ chance of occurring each year".

\subsubsection{Make resources available for ex-ante risk reduction}

In both the Nepal and Morocco PERCs, the issue of financing for disaster risk reduction is raised as a significant barrier to undertaking this much-needed investment. This is related to the lesson above on the need to improve incentives for selfprotection and building back better in the face of repetitive losses. Individuals, communities, governments, and INGOs suffer from disincentives to invest enough in ex-ante risk reduction. We pick up on this point again in our conclusion as a potential future direction for PERC.

\subsubsection{Cross-jurisdictional coordination is difficult but essential}

Cross-jurisdictional coordination (either intra- or international) is a recurrent theme throughout the PERCs. The central European flood PERC shows how coordination between states in Germany greatly improved crisis intervention. Similarly in the Emmental floods, cross-canton coordination to manage flood water flows has improved substantially since previous floods and contributed significantly to loss reduction in 2014. The Balkan floods PERC contrasts success in coordination within Serbia, which has a relatively strong central government, with Bosnia and Herzegovina, where internal divisions are creating difficulties and inefficiencies in response operations. The difficulty but importance of cross-jurisdictional coordination also came out strongly in the Nepal PERC, where downstream dams in India are contributing to waterlogging and flooding in Nepal. 
Despite difficulties, cross-jurisdictional coordination is fundamental to disaster risk management because disasters do not respect jurisdictional boundaries. As highlighted in the Morocco PERC, there is currently no coordination or information sharing between Morocco and neighbouring countries on their common risks. Lack of cross-jurisdictional coordination is not only inefficient, it often completely hampers efforts to enhance disaster resilience. The goal here is to widely operationalise a practical application of a wellestablished concept as well as holistic and integrated flood risk management.

\subsubsection{Community engagement is essential}

The fundamental importance of engaging communities and wider stakeholders in all aspects of disaster risk management and resilience building is established recurrently throughout the collection of PERC reports, both in developed and developing country contexts. The central European flood PERC highlighted the importance of community engagement in the levee planning process, since competing values and preferences need to be integrated into the design if it is to be accepted. This report also identified that the implementation and success of polders is dependent on community acceptance, demonstrating the importance of, and benefits to be gained by, engaging communities early and often in the disaster risk discourse. In the Karnali basin in Nepal, it was community disaster management committees who provided the vast majority of effective responses, demonstrating the power of community action. The Karnali PERC also emphasises the need to engage communities in making decisions about risk reduction, as how they interact with the physical and natural environment is a key component to the success or failure of both physical and natural defense infrastructure initiatives. The Morocco PERC found that a general atmosphere of mistrust in authority during normal times hampered community-authority coordination during the floods, highlighting the importance of ongoing engaged governance.

\subsection{Future directions for improving the PERC methodology}

In the process of conducting this review to draw out the salient lessons identified above, we have also identified a number of strengths and weaknesses in the methodology itself, which, in the spirit of iterative learning, should be incorporated into PERC work. The first insight is that the PERCs which focus on addressing underlying trends in the drivers of risk (namely vulnerability and exposure) are more successful at integrating with the movement towards disaster resilience. These also speak more profoundly to the most pressing need in the disasters field, which is to arrest exposure growth. This insight has already been incorporated into the PERC guide (Venkateswaran et al., 2015), and is indeed now a firmly established component of the meta-structure.
The second lesson we have identified from this analysis relates to the recurrent insight on disaster risk awareness. For example, the central European flood PERC strongly recommends the need for targeted information to individuals and businesses to improve disaster risk awareness and suggests that this is a necessary (but not sufficient) condition for taking action. Considering the centrality of disaster risk awareness to the disaster risk management discourse, future PERCs could explore the relative success or failures of these types of information campaigns when they have been implemented prior to the disaster being investigated. Similarly, both the Nepal and Morocco flood PERCs recommend increasing availability of resources for ex-ante risk reduction. One future direction for the PERCs could be to explore the circumstances of why this is or is not happening and identify success stories in addressing it.

The experience and resultant PERC reports from Boulder, Morocco, and Nepal demonstrate a depth of insight gained when local partners are embedded in or driving the process. Local partners provide the analyst with both insight and understanding of the local context, as well as connections for accessing information and potential interviewees. We note that the Morocco floods PERC included 30 household surveys, conducted by the local NGO partner. While this sample size was quite small, it provided extremely valuable insight which comes through in the PERC analysis.

\section{Conclusion and way forward}

We started our discussion by suggesting that five elements are part and parcel of effective forensic analysis: root cause analysis, meta-analytical reviews, longitudinal analysis, retrospective scenarios, and effective communication. With some caveats, we suggest that PERCs are effective means of addressing many of these, with good potential for addressing others as well. We have presented the ever-evolving PERC methodology, a systematic approach to forensic disaster investigation which is both consistent and flexible. The PERC methodology is grounded in its thinking on disaster resilience, and in particular aims to go beyond exclusive focus on disaster risk management as it has been traditionally conceptualised. At the same time, PERC reports are designed to be accessible and recommendations actionable, within current institutional arrangements. They aim to speak primarily to practitioners and policy makers by striking a balance between understanding underlying trends and identifying concrete opportunities for action.

We have conducted a meta-analysis of the content of the PERCs conducted to date. While much of the information is context-specific, we have drawn out a number of salient, recurrent lessons. Our analysis finds striking similarities in challenges across extremely varied contexts. The fact that the meta-structure of the PERC is based on a resilience mentality, and these recurrent insights, leads us to conclude that 
such an approach has utility for identifying generalisable lessons about disaster risk management and resilience more broadly. We recognise, however, that the strength of this type of analysis will only grow as more PERCs are carried out.

It is not enough to understand the dynamics of disaster risk and resilience, what went wrong and what worked well in the disaster risk management cycle. This learning is a necessary first step, but must be turned into action. This type of learning can, and does, take many forms. However, the PERC methodology has been designed specifically to facilitate turning learning into action. Compared to other disaster forensic approaches, PERCs can be carried out relatively quickly and inexpensively; in this way PERCs can be available when attention is still turned to questions of disaster risk, reconstruction decisions are still being made, and disaster policies are being revisited. Fundamental to PERCs are actionable recommendations, which allow for learning to be turned into action before the next disaster occurs. PERCs are carried out in partnership with local organisation to ensure full insight into local issues, access to relevant informants, and subsequent dissemination and uptake. Finally, PERCs (and associated summaries and other materials) are designed to be accessible to all stakeholders, so that learning may be utilised by all.

By systematically addressing trends in the underlying drivers of risk, PERCs help to understand the root causes of growing disaster risk. In combination with the metaanalytical review conducted in this paper, patterns of causes and drivers of risk can be isolated. Due to its recent set-up, PERCs currently do not cover longitudinal analysis, but with the analysis rolled out in various locations across the globe, the approach will be useful for studying disaster resilience over time. A further future direction being explored is the potential for PERCs which provide for developing retrospective scenarios to be tested against reality.

The focus within the PERC approach of taking a holistic perspective of disaster risk, DRM, and disaster resilience, has been informed by the 5C-4R approach to understanding and measuring community flood resilience within the Zurich Flood Resilience Alliance (Keating et al., 2014; Keatin et al., 2016). This framing of disaster resilience follows the Sustainable Livelihood Framework's (DFID, 1999) five capitals, which emphasises the importance of human, social, and environmental factors, in addition to physical and financial ones, in maintaining and enhancing well-being. All these factors are also critical for effective disaster risk management. MCEER (2006) defines four properties of a resilient system (4Rs); while these were set out originally for a built, engineered system relating to earthquakes, we believe these are pertinent not only to tangible, structural aspects but also to the intangible ones. As such they have been adapted for this purpose. The 4 Rs are robustness (ability to withstand a shock), redundancy (functional diversity), resourcefulness (ability to mobilise when threatened), and rapidity (ability to contain losses and recovery in a timely manner). The mix and utilisation of capitals allows for the realisation of resilience via the 4 Rs when a disaster strikes. There is potential to more explicitly link the PERC approach to other work framed in this way, in particular to a substantial measurement initiative currently underway, in order to continue to build an insight into the critical factors which allow for a resilient outcome.

The PERC methodology is adaptable and flexible, so it can address different scopes, scales, and time frames as required. We anticipate that this flexibility will allow the methodology to be utilised for different types of learning while maintaining the core fundamentals of the systemic perspective encompassing disaster resilience, and a useful level of comparability. Some adapted types of PERCs might include a retrospective PERC conducted using remotely sourced materials and interviews; "mini-PERCs", which look at smaller scales or focus on specific questions; and PERCs, which take a historical look at multiple events to track changes and learn over time.

Learning does not only need to happen within individual contexts; we have seen significant potential for learning from other events/locations, and for the disaster field as a whole to consolidate this knowledge. The PERC approach is freely available and its adoption is encouraged to build the repository of learnings. The freely available repository itself is being designed to be searchable so that successes and insights around particular themes can be accessed by those wanting to learn from the experiences documented in the PERCs. The consistent meta-structure of the PERC reports allows for useful meta-analysis and comparison.

Acknowledgements. The authors would like to acknowledge funding provided by the Zurich Foundation via the Zurich Flood Resilience Alliance, the authors of the PERC reports, and reviewers.

Edited by: K. Schröter

Reviewed by: N. Walliman and one anonymous referee

\section{References}

Benson, C. and Twigg, J.: Measuring mitigation: methodologies for assessing natural hazard risks and the net benefits of mitigation, International Federation of Red Cross and Red Crescent Societies (IFRC), ProVention Consortium, Geneva, 2004.

Birkland, T.: Disasters, Lessons Learned, and Fantasy Documents, J. Conting. Crisis Manage., 17, 146-157, 2009.

Bull-Kamanga, L, Diagne, K., Lavell, A., Leon, E., Lerise, F., MacGregor, H., Maskrey, A., Meshack, M., Pelling, M., Reid, H., Satterthwaite, D., Songsore, J., Westgate, K. and Yitambe, A.: From everyday hazards to disasters: the accumulation of risk in urban areas, Environ. Urb., 15, 193-203, 2003.

Burton, I.: Forensic disaster investigations in depth: A new case study model, Environment, 52, 36-41, 2010.

Cardona, O.: The Need for Rethinking the Concepts of Vulnerability and Risk from a Holistic Perspective: A Necessary Review and Criticism for Effective Risk Management, in: Chapter 3 
in Mapping Vulnerability: Disasters, Development and People, edited by: Bankoff, G., Frerks, G., and Hilhorst, D., Earthscan Publishers, London, 2003.

CEDIM: Forensic Disaster Analysis, Center for Disaster Management and Risk Reduction Technology, Karlsruhe Institute of Technology, https://www.cedim.de/english/2131.php (last access: 6 June 2016), 2015.

CRED: The Human Cost of Natural Disasters 2015: A global perspective, Centre for Research on Epidemiology of Disasters, Université catholique de Louvain, Brussels, Belgium, 2015.

DFID: Sustainable Livelihoods Guidance Sheets, Department of International Development, United Kingdom, http://www.eldis.org/vfile/upload/1/document/0901/section2.pdf (last access: 6 June 2016), 1999.

Donahue, A. and Tuohy, R.: Lessons We Don't Learn: A Study of the Lessons of Disasters, Why We Repeat Them, and How We Can Learn Them, Homeland Security Affairs, https://www.hsaj. org/articles/167 (last access: 6 June 2016), 2006.

EEFIT: The Earthquake Engineering Field Investigation Team, The Institution of Structural Engineers, https: //www.istructe.org/resources-centre/technical-topic-areas/eefit (last access: 6 June 2016), 2016.

Erikson, K. T.: Everything in its path: Destruction of community in the Buffalo Creek Flood, Simon and Schuster, New York, 1976.

Friend, R. and MacClune, K.: Climate resilience framework: Putting resilience into practice, Institute for Social and Environmental Transition-International, Boulder, CO, 2012.

GFDRR: Damage, Loss and Needs Assessment, Guidance Notes, The International Bank for Reconstruction and Development/The World Bank, Washington, D.C., 2010.

GFDRR: Post-Disaster Needs Assessments, Volume A, Guidelines, Global Facility for Disaster Risk Reduction, https: //www.gfdrr.org/sites/gfdrr/files/PDNA-Volume-A.pdf (last access: 6 June 2016), 2013.

Gunderson, L.: Ecological and human community resilience in response to natural disasters, Ecol. Soc., 15, 18, 2010.

Hoff, H., Bouwer, L., Berz, G., Kron, W., and Loster, T.: Risk Management in Water and Climate - the Role of Insurance and Other Financial Services, Munich Reinsurance Company, Munich, 2003.

IPCC: Managing the Risks of Extreme Events and Disasters to Advance Climate Change Adaptation, in: A Special Report of Working Groups I and II of the Intergovernmental Panel on Climate Change, edited by: Field, C. B., Barros, V., Stocker, T. F., Qin, D., Dokken, D. J., Ebi, K. L., Mastrandrea, M. D., Mach, K. J., Plattner, G.-K., Allen, S. K., Tignor, M., and Midgley, P. M., Cambridge University Press, Cambridge, UK, and New York, NY, USA, 2012.

IRDR: Forensic Investigations of Disasters: The FORIN Project, IRDR FORIN Publication No. 1, Integrated Research on Disaster Risk, Beijing, 2011.

Jones, L. M., Bernkopf, R., Cox, D., Goltz, J., Hudnet, K., Miletti, D., Perry, S., Ponti, D., Porter, K., Reichle, M., Seligman, H., Shoaf, K., Treiman, J., and Wien, A.: The shakeout scenario, US Geological Survey Open File Report No. 2008-1150 and California Geological Survey Preliminary Report No. 25, 2008.

Jongman, B., Hochrainer-Stigler, S., Feyen, L., Aerts, J., Mecher, R., Botzen, W., Bouwer, L., Pflug, G., Rodrigo, R., and Ward, P.:
Increasing stress on disaster risk finance due to large floods, Nat. Clim. Change, 4, 264-268, 2014.

Keating, A., Campbell, K., Mechler, R., Michel-Kerjan, E., Mochizuki, J., Kunreuther, H., Bayer, J., Hanger, S., McCallum, I., See, L., Williges, K., Atreya, A., Botzen, W. Collier, B., Czajkowski, J., Hochrainer, S., and Egan, C.: Operationalizing Resilience Against Natural Disaster Risk: Opportunities, Barriers and A Way Forward, Zurich Flood Resilience Alliance, http://opim.wharton.upenn.edu/risk/library/ zurichfloodresiliencealliance_ResilienceWhitePaper_2014.pdf (last access: 6 June 2016), 2014.

Keating, A., Campbell, K., Szoenyi, M., McQuistan, C., Nash, D., and Burer, M.: Development and testing of a community flood resilience measurement tool, Nat. Hazards Earth Syst. Sci. Discuss., doi:10.5194/nhess-2016-188, in review, 2016.

Kellett, J. and Caravani, A.: Financing disaster risk reduction: A 20year story of international aid, ODI and the Global Facility for Disaster Reduction and Recovery at the World Bank, London, Washington, 2013.

Lavell, A. and Maskrey, A.: The future of disaster risk management, Environ. Hazards, 13, 267-280, doi:10.1080/17477891.2014.935282, 2014.

MacClune, K., Allan, C., Venkateswaran, K., and Sabbag, L.: Floods in Boulder: A Study of Resilience, ISET-International, Boulder, CO, http://i-s-e-t.org/resources/case-studies/ floods-in-boulder.html (last access: 6 June 2016), 2014.

MacClune, K., Venkateswaran, K., Dixit, K. M., Yadav, S., Maharjan, R., and Dugar, S.: Urgent case for recovery: what we can learn from the August 2014 Karnali River floods in Nepal, Zurich Insurance Group, ISETInternational, ISET-Nepal and Practical Action Nepal, https://www.zurich.com/_/media/dbe/corporate/knowledge/ docs/risk-nexus-karnali-river-floods-nepal-july-2015.pdf?la=en (last access: 6 June 2016), 2015.

MCEER: MCEER's Resilience Framework, MCEER, University of Buffalo, http://mceer.buffalo.edu/research/resilience/Resilience_ 10-24-06.pdf (last access: 6 June 2016), 2006.

Mechler, R.: Reviewing estimates of the economic efficiency of disaster risk management: Opportunities and limitations of using risk-based Cost-Benefit Analysis, Nat. Hazards, 81, 2121, doi:10.1007/s11069-016-2170-y, 2016.

Meyer, B.: Why We Still Fail to Learn from Disasters, in: chap. 15 in The Irrational Economist, edited by: Michel-Kerjan, E. and Slovic, P., Public Affairs, New York, 2010.

Mitchell, J. K.: Megacities and Natural Disasters: A Comparative Analysis, GeoJournal, 49, 137-142, 1999.

Munich Re: Natural catastrophes 2014: Analyses, assessments, positions, Topics Geo 2015 issue, http://www.munichre.com/site/ corporate/get/documents_E1018449711/mr/assetpool.shared/ Documents/5_Touch/_Publications/302-08606_en.pdf (last access: 6 June 2016), 2014.

Oliver-Smith, T. and Hoffman, S. (Eds.): The angry Earth: Disaster in anthropological perspective, Routledge, New York, 1999.

Swiss Re: Natural catastrophes and man-made disasters in 2014, Sigma 2/2015, http://media.swissre.com/documents/sigma2 2015_en.pdf (last access: 6 June 2016), 2015.

Szoenyi, M., Venkateswaran, K., Keating, A. and MacClune, K.: After the flood is before the next flood: The post event review capability (PERC) methodology developed by Zurich's flood re- 
silience alliance, in: chapter submitted to Flood Damage Survey and Assessment: New Insights from Research and Practice, edited by: Molinari, D., Menoni, S., and Ballio, F., AGU Books, Wiley, Blackwell, in revision, 2016.

Tyler, S. and Moench, M.: A framework for urban climate resilience, Clim. Dev., 4, 311-326, 2012.

UNISDR: From Shared Risk to Shared Value -The Business Case for Disaster Risk Reduction, United Nations Office for Disaster Risk Reduction, Geneva, 2013.

UNISDR: Global Assessment Report on Disaster Risk Reduction - Making Development Sustainable: The Future of Disaster Risk Management, United Nations Office for Disaster Risk Reduction, Geneva, http://www.preventionweb.net/english/hyogo/gar/2015/ en/gar-pdf/GAR2015_EN.pdf (last access: 6 June 2016), 2015.

United Nations: Hyogo Framework for Action 2005-2015: Building the Resilience of Nations and Communities to Disasters, A/CONF.206/6, 22 January 2005, available at: http://www. refworld.org/docid/42b98a704.html (last access: 6 June 2016), 2005.

United Nations: Sendai Framework for Disaster Risk Reduction 2015-2030, A/CONF.224/CRP.1, 18 March 2015, available at: http://www.wcdrr.org/uploads/Sendai_Framework_ for_Disaster_Risk_Reduction_2015-2030.pdf (last access: 6 June 2016), 2015.

UNISDR: Terminology on Disaster Risk Reduction, United Nations International Strategy for Disaster Risk Reduction, Geneva, Switzerland, http://www.unisdr.org/files/7817_ UNISDRTerminologyEnglish.pdf (last access: 6 June 2016), 2009.

Venkateswaran, K., MacClune, K., Keating, A., and Szönyi, M.: Learning from Disasters to Build Resilience: A Simple Guide to Conducting a Post Event Review, ISET-International \& Zurich Insurance Group, Boulder, CO, https://www.zurich.com/_/media/dbe/corporate/docs/ corporate-responsibility/the-perc-manual.pdf (last access: 6 June 2016), 2015.
White, G. F., Kates, R. W., and Burton, I.: Knowing better and losing even more: The use of knowledge in hazards management, Environ. Hazards, 3, 81-92, 2001.

Wisner, B., Blaikie, P., Cannon, T., and Davis, I.: At Risk: Natural Hazards, People's Vulnerability, and Disasters, 2nd Edn., Routledge, London, 2004.

Zurich Insurance Group: Emmental, Switzerland floods of July 2014: On a hot, sunny day, a flood alert!, Zurich Insurance Company, https://www.zurich.com/_/media/dbe/corporate/docs/ whitepapers/perc-emmental-flooding-july-2014.pdf?la=en (last access: 6 June 2016), 2014a.

Zurich Insurance Group: Risk Nexus: After the storm: how the UK's flood defences performed during the surge following Xaver, Zurich Insurance Company, https: //www.zurich.com/_/media/dbe/corporate/docs/whitepapers/ risk-nexus-september-2014-uk-floods-2013.pdf?la=en (last access: 6 June 2016), 2014b.

Zurich Insurance Group: Risk Nexus: Central European floods 2013: a retrospective, Zurich Insurance Company, https: //www.zurich.com/_/media/dbe/corporate/docs/whitepapers/ risk-nexus-may-2014-central-european-floods-2013.pdf?la=en (last access: 6 June 2016), 2014c.

Zurich Insurance Group: Balkan floods of May 2014: challenges facing flood resilience in a former war zone, Zurich Insurance Company, https://www.zurich.com/_/media/dbe/corporate/docs/ corporate-responsibility/flood-resilience-balkan-may-2015.pdf (last access: 6 June 2016), 2015.

Zurich Insurance Group and Targa-AIDE: Risk Nexus: Morocco floods of 2014: what we can learn from Guelmim and Sidi Ifni, Zurich Insurance Company and Targa-AIDE, https://www.zurich.com/_/ media/dbe/corporate/docs/corporate-responsibility/ risk-nexus-morocco-floods-of-2014-november-2015.pdf?la=en (last access: 6 June 2016), 2015. 